\title{
CARACTERIZAÇÃO PALEOAMBIENTAL DE DEPÓSITOS EOCÊNICOS DA BACIA DE SERGIPE-ALAGOAS, BRASIL, COM BASE EM MORFOGRUPOS DE FORAMINÍFEROS BENTÔNICOS E PALINOMORFOS
}

\author{
FRANCO BORGES QUADROS \\ Petrobras, Exploração \& Produção, Av. República do Chile, 330, 20031-170, Rio de Janeiro, RJ, Brasil. \\ franco.quadros@petrobras.com.br \\ ELIZABETE PEDRÃO FERREIRA, MARTA CLAUDIA VIVIERS, DENIZE SANTOS COSTA \\ Petrobras/Cenpes, Rua Horácio Macedo, 950, 21941-915, Rio de Janeiro, RJ, Brasil. \\ elizabete@petrobras.com.br,mcviviers@outlook.com,denizesc@petrobras.com.br \\ CLAUDIA GUTTERRES VILELA \\ Instituto de Geociências, UFRJ, Av. Athos da Silveira Ramos, 274, 21941-916, Rio de Janeiro, RJ, Brasil. \\ vilela@geologia.ufrj.br
}

\begin{abstract}
PALEOENVIRONMENTAL CHARACTERIZATION OF EOCENE DEPOSITS FROM SERGIPEALAGOAS BASIN, BRAZIL, BASED ON FORAMINIFERA MORPHOGROUPS AND PALYNOMORPHS. A large morphological variety found in benthic foraminifera tests is attributed to their ability of adaptation to environmental changes. Grouping the taxa by morphological similarities has shown to be an effective tool to paleoenvironmental reconstructions. Thus, foraminifera of middle Eocene strata of well SE-2, Sergipe-Alagoas Basin, were studied. Between the 13 foraminifera morphogroups identified in this section, the calcareous-hyaline (CH-A.6, CH-B.4 and CH-A.5) are the most representatives. Abundance plots of other foraminifera groups (planktonic $v s$. benthic, epifaunal $v s$. infaunal benthic, and main genera of calcareous-hyaline types) supported the paleoecological interpretations. The occurrence of a macro-scale foraminifera group associated to terrestrial palynomorphs in some intervals is interpreted as periods of relative lowering sea level. The integration of foraminifera, palynomorphs, and isotopic data suggests that sedimentation occurred in middle Eocene under superior bathyal to deep neritic conditions in cold waters around de SE-2 area. There is a direct relationship between a group of palynomorphs and the relative abundances of some genera of benthic foraminifera (Bulimina, Eponides and Globobulimina), which suggest a high organic productivity and low oxygen bottom waters at these intervals.
\end{abstract}

Key words: benthic foraminifera, morphogroups, palynomorphs, Eocene, paleoenviromnent.

RESUMO - A grande variedade morfológica encontrada nas carapaças dos foraminíferos é atribuída a sua capacidade de adaptação às mudanças ambientais. $\mathrm{O}$ agrupamento dos táxons em morfogrupos mostra-se uma ferramenta eficaz quando aplicada em reconstruções paleoambientais. Assim, sob esta ótica foram estudados os foraminíferos presentes nos sedimentos do Eoceno médio do poço SE-2, bacia de Sergipe/Alagoas. Dentre os 13 morfogrupos funcionais de foraminíferos bentônicos reconhecidos no intervalo, os calcário-hialinos (CH-A.6, CH-B.4 e CH-A.5) são os mais representativos. A avaliação de gráficos de abundância entre outros grupos de foraminíferos (planctônicos $v s$. bentônicos; bentônicos epifaunais $v s$. infaunais, além da distribuição dos gêneros calcário-hialinos e dos morfogrupos) deram suporte às interpretações paleoecológicas. A ocorrência de um grupo denominado macroforaminíferos bem como a presença de palinomorfos continentais, em alguns intervalos, são interpretadas como momentos de rebaixamento relativo do nível de base. A integração dos dados de foraminíferos, palinomorfos e isótopos sugere que a sedimentação do Eoceno médio ocorreu em condição batial superior a nerítico profundo e em águas frias na região do poço SE-2. Há correlação direta entre grupos de palinomorfos marinhos e as abundâncias de alguns gêneros de foraminíferos bentônicos infaunais (Bulimina, Eponides e Globobulimina), que sugerem condições de alta produtividade orgânica e água de fundo deficiente em oxigênio nestes intervalos.

Palavras-chave: foraminífero bentônico, morfogrupos, palinomorfos, Eoceno, paleoambiente. 


\section{INTRODUÇÃO}

Os foraminíferos, que nos dias atuais ocupam preferencialmente os ambientes marinhos, possuem uma carapaça ou teca constituída por uma ou várias câmaras conectadas entre si por um orifício denominado forâmen. A carapaça é formada pela aglutinação de partículas disponíveis no ambiente em que vivem, ou secretada pelo próprio organismo, sendo a composição predominantemente carbonática, e, mais raramente, orgânica ou silicosa. Para Goldstein (1999), os foraminíferos pertencem ao Reino Protista (Filo Sarcodina, Classe Rhizopoda, Ordem Foraminifera) por constituírem um grupo de organismos unicelulares. Todavia, a existência de formas multicelulares entre os táxons permitiu a Sen Gupta (1999) propor a inserção dos mesmos no Reino Protoctista (Filo Granuloreticulosa, Classe Foraminifera).

O modo de vida dos foraminíferos varia entre planctônicos e bentônicos. Os primeiros flutuam nas águas oceânicas, enquanto os bentônicos, pela sua relação com o substrato, podem ser sésseis ou vágeis. Os foraminíferos bentônicos podem ser diferenciados pelo hábito de vida em epifaunais, dispostos sobre os sedimentos, e, infaunais, quando ficam soterrados nos sedimentos. Como seres vivos, sua distribuição é consequência dos fatores bióticos próprios do táxon e dos fatores abióticos que regem o meio. Os fatores de controle bióticos relevantes são: o ciclo de vida, a alimentação, a composição e a morfologia das carapaças. A salinidade, temperatura, tipo de substrato, turbidez da água, luminosidade, nutrientes, nível de oxigênio e energia se destacam entre os fatores abióticos pela grande influência sobre este grupo (Murray, 1991).

Particularmente nos estudos paleoambientais, os foraminíferos bentônicos são excelentes indicadores de fatores abióticos, sugeridos pela estreita relação entre esses organismos fósseis e o meio em que habitavam. Isso permite avaliar as características do seu modo de vida, dos microhabitats que ocupavam e dos agentes que atuaram nos processos de soterramento post-mortem (Jackson, 1997).

Em razão das funções que a carapaça desempenha no ciclo de vida dos foraminíferos bentônicos (estratégia de alimentação e nos hábitos de vida) estas apresentam grande variabilidade morfológica. A adoção de um tipo morfológico (morfotipo), muitas das vezes, revela a adaptação dos foraminíferos às circunstâncias ambientais, especialmente à estrutura trófica vigente (Severin, 1983). A adaptação desses organismos de estrutura biológica simples à diversidade de nichos ecológicos que ocupam faz deles uma ferramenta eficaz para estudos de natureza ecológica e paleoecológica (Corliss, 1983; Koutsoukos \& Hart, 1990).

Nas últimas décadas, os foraminíferos bentônicos vêm sendo estudados a partir do agrupamento dos táxons em morfogrupos com base na similaridade morfológica das carapaças. Os resultados dos estudos dos morfogrupos incrementam o nível de compreensão das relações das associações que ocupavam diferentes microhabitats (do Cretáceo até os depósitos atuais) e dos parâmetros mais importantes que caracterizam o meio (Severin, 1983; Jones \& Charnock, 1985; Koutsoukos \& Hart, 1990; Costa, 2004).
Neste contexto, utilizando o conceito de morfogrupos, Koutsoukos \& Hart (1990) reconheceram padrões na distribuição paleoambiental das associações de foraminíferos bentônicos da seção cretácea da bacia de Sergipe. O objetivo principal do presente trabalho é mostrar os resultados da aplicação dos morfogrupos de foraminíferos bentônicos nos estudos paleoambientais dentro de um arcabouço bioestratigráfico integrado da seção eocênica com base em foraminíferos planctônicos, nanofósseis calcários e palinomorfos. Foram comparados os resultados paleoambientais com base nas associações de foraminíferos bentônicos e de palinomorfos e integrados com os dados de isótopos estáveis (oxigênio e carbono).

\section{ÁREA DE ESTUDO}

A bacia de Sergipe/Alagoas está localizada ao longo da costa nordeste brasileira abrangendo os estados de Sergipe e Alagoas, entre as latitudes $9^{\circ}$ e $11^{\circ} 30^{\prime} \mathrm{S}$ e longitudes $37^{\circ} 30^{\prime}$ e $35^{\circ} \mathrm{W}$ (Figura 1). A bacia abrange uma área total de $42.400 \mathrm{~km}^{2}$, sendo que a sua porção submersa se estende aproximadamente até a isóbata de $3.000 \mathrm{~m}$ com uma área de aproximadamente $30.000 \mathrm{~km}^{2}$ (Feijó, 1994).

A bacia de Sergipe-Alagoas está limitada ao norte pela bacia de Pernambuco-Paraíba, a sul pela bacia de Camamu, e a oeste pela Província de Borborema (Souza-Lima, 2006). Esta bacia pode ser dividida em quatro sub-bacias a partir do seu caráter estrutural e estratigráfico: Cabo, Alagoas, Sergipe e Jacuípe (Campos Neto et al., 2007). O preenchimento sedimentar da bacia compreende estratos do Paleozoico ao Recente, sendo alvo deste trabalho apenas os depósitos do Grupo Piaçabuçu. Este grupo é constituído por três formações que se interdigitam: Marituba, Mosqueiro e Calumbi (Feijó, 1994; Campos Neto et al., 2007).

Na Formação Marituba predominam arenitos médios e grossos, cinzentos, que foram depositados em leques costeiros que gradam lateralmente para a Formação Mosqueiro. Esta é caracterizada pela predominância de calcarenito bioclástico, composto basicamente por foraminíferos e moluscos. Os sedimentos da Formação Mosqueiro gradam para argilitos e folhelhos com intercalações de arenitos finos a grossos da Formação Calumbi (Feijó, 1994). O intervalo estudado neste trabalho, com cerca de $1.500 \mathrm{~m}$ de espessura, corresponde aos estratos do Paleoceno-Eoceno da Formação Calumbi, do Baixo de Mosqueiro (Ferreira, 2004). De acordo com Campos Neto et al. (2007), as três unidades litoestratigráficas que compõem o Grupo Piaçabuçu foram depositadas em estágio de subsidência térmica, que ocorreu inicialmente em condições marinhas restritas e, posteriormente, em mar aberto.

\section{MATERIAL E MÉTODOS}

Para a aplicação do modelo de morfogrupos de foraminíferos de Koutsoukos \& Hart (1990) foi selecionado o poço exploratório SE-2 localizado na bacia de Sergipe/ Alagoas, nordeste do Brasil (Figura 1). A seção paleocênicaeocênica do poço SE-2 possui cerca de $900 \mathrm{~m}$ de sedimentos 


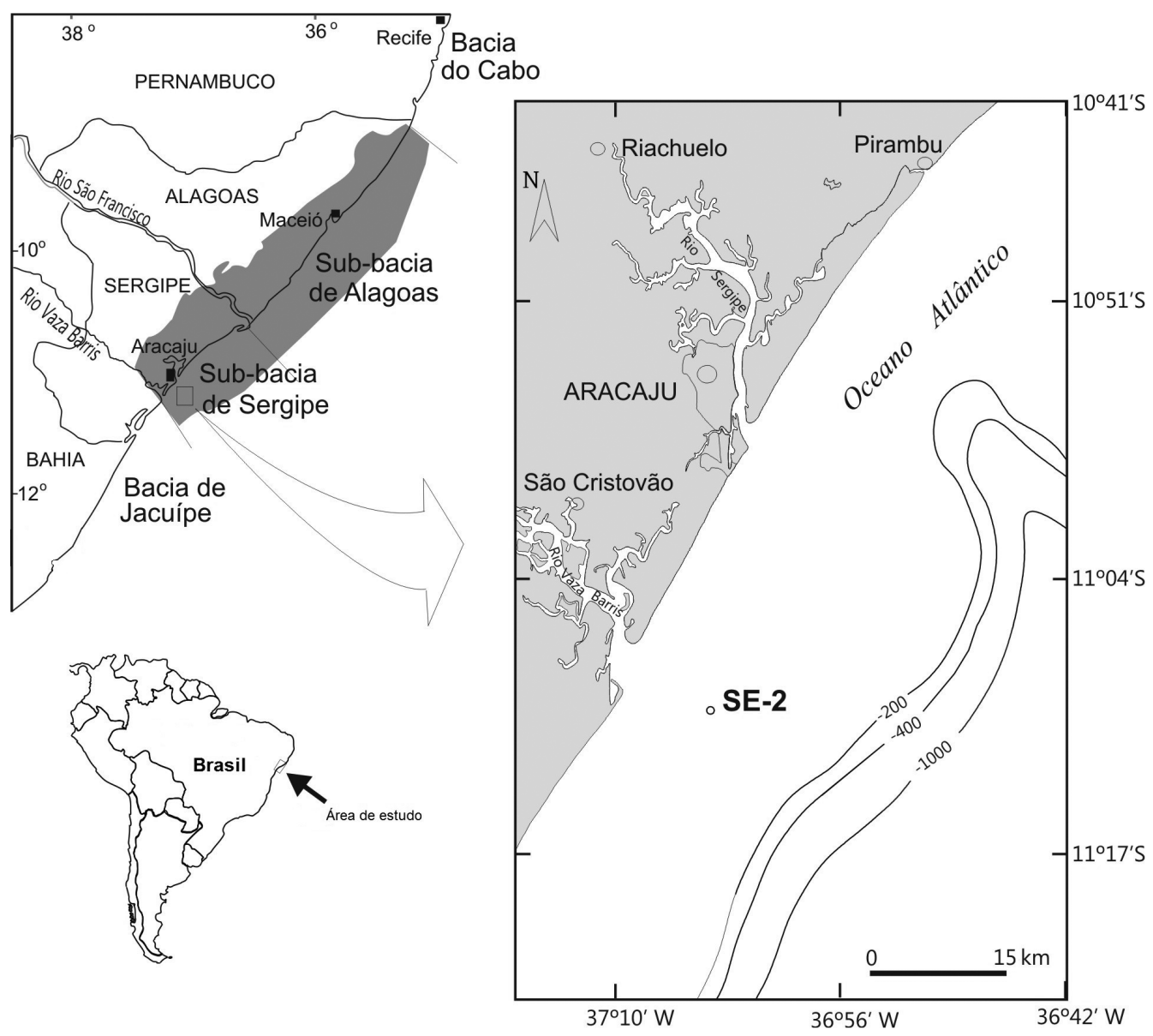

Figura 1. Mapa de localização da sub-bacia de Sergipe e do poço estudado (modificado de Ferreira, 2004).

Figure 1. Location map of Sergipe sub-basin and the studied well (modified from Ferreira, 2004).

predominantemente siliciclásticos, contendo uma rica e bem preservada associação microfossilífera (Ferreira, 2004). $\mathrm{O}$ estudo das associações de foraminíferos bentônicos foi realizado em 18 amostras de calha, coletadas do intervalo 858-642 $\mathrm{m}$ (216 $\mathrm{m}$ de espessura), com espaçamento variando entre 9 e $18 \mathrm{~m}$.

A preparação e as análises dos foraminíferos foram realizadas nos laboratórios de micropaleontologia das dependências da Petrobras/Cenpes/Gerência de Bioestratigrafia e Paleoecologia e da UFRJ/DEGEO, localizados no município do Rio de Janeiro. O processamento consistiu em tratar cada amostra (60 g) com solução de peróxido de hidrogênio a 130 volumes para desagregação dos sedimentos e liberação dos microfósseis. Em seguida, cada amostra foi lavada em água corrente em um conjunto de peneiras de malhas de $1,00 \mathrm{e}$ $0,0625 \mathrm{~mm}$. O material retido na peneira de $1,00 \mathrm{~mm}$ foi seco em uma estufa a $120^{\circ} \mathrm{C}$. A etapa de triagem consistiu na passagem de cada amostra por um conjunto de peneiras (malha $0,500 \mathrm{~mm} ; 0,250 \mathrm{~mm} ; 0,125 \mathrm{~mm}$ ) e para o estudo taxonômico e sistemático foram separados 150 microfósseis retidos na peneira de malha $0,250 \mathrm{~mm}$.

Os foraminíferos foram estudados em uma lupa binocular da marca Leica, modelo MZ 12.5, com aumento máximo de 100x. As análises foram complementadas com a contagem dos espécimes por táxon, que serviram como fonte de dados para as interpretações paleoecológicas. Apenas os espécimes melhor preservados e de significado bioestratigráfico e paleoecológico foram selecionados para captura de imagem no Microscópio Eletrônico de Varredura (MEV).

A escolha do poço SE-2 entre outros poços analisados por palinomorfos, foraminíferos, nanofósseis calcários e por isótopos de oxigênio e carbono no Baixo de Mosqueiro, deve-se às evidências de mudanças climáticas globais e paleoceanográficas assinaladas por Zachos et al. (1993) e reconhecidas no intervalo Paleoceno-Eoceno da bacia de Sergipe por Ferreira (2004).

Os eventos termais de aquecimento ocorridos no Paleoeceno-Eoceno inferior e identificados no Baixo de Mosqueiro foram Benthic Foraminiferal Extinction (BFE) (Viviers \& Ferreira, 2006a,b) e Paleocene-Eocene Thermal Maximum (PETM) (Ferreira, 2004; Ferreira et al., 2006). No intervalo subsequente (Eoceno médio-superior) foi registrada uma tendência de resfriamento, a qual foi interrompida por um rápido evento de aquecimento, Middle Eocene Climatic Optimum (MECO) (Ferreira, 2004; Maizatto et al., 2004; Ferreira et al., 2009; Premaor et al., 2013). É importante 
a compreensão dos processos ocorridos no Eoceno, pois representa um período climático de transição entre condições de greenhouse para icehouse, que preparou as condições modernas de vida e clima (Bohaty \& Zachos, 2003; Zachos et al., 2008; Vanderberghe et al., 2012).

A identificação dos foraminíferos planctônicos seguiu os trabalhos de Bolli et al. (1985), Spezzaferri (1994), Martinis (1996), Iaccarino \& Premoli Silva (2005) e Pearson et al. (2006). Entretanto, para o estudo dos foraminíferos bentônicos usou-se principalmente os trabalhos de Loeblich \& Tappan (1988) e Bolli et al. (1994). Os arcabouços bioestratigráficos utilizados como referência são: o proposto por Noguti \& Santos (1972) para as bacias brasileiras, e os arcabouços internacionais de Berggren et al. (1995) e Berggren \& Pearson (2005). As idades aqui adotadas são aquelas apresentadas em Gradstein et al. (2012).

A reunião dos foraminíferos em morfogrupos funcionais seguiu os critérios apresentados em Koutsoukos \& Hart (1990) para a seção aptiana-maastrichtiana da bacia de Sergipe. A caracterização de morfogrupos funcionais de foraminíferos definidos por Costa (2004) para a seção santoniana-maastrichtiana da bacia do Ceará também foi utilizada como referência.

\section{RESULTADOS}

\section{Composição da microfauna de foraminíferos}

Os foraminíferos identificados no poço SE-2 estão distribuídos nas subordens Textulariina, Miliolina, Lagenina, Robertinina, Rotaliina e Globigerinina. Com exceção de Globigerinina que contém formas planctônicas, os demais grupos englobam foraminíferos bentônicos. No intervalo estudado foram reconhecidos táxons pertencentes a 24 superfamílias, 44 famílias, 30 subfamílias e 73 gêneros.

Os foraminíferos planctônicos identificados estão incluídos em duas superfamílias: Globorotaliaceae (Globorotaliidae) e Globigerinaceae (Globigerinidae, Truncorotaloididae, Globoquadrinidae, Hedbergellidae e Candeinidae). Os táxons planctônicos identificados no poço estão distribuídos em 17 gêneros comportando 52 espécies, as quais se encontram listadas no Anexo 1. Os táxons mais importantes para a caracterização bioestratigráfica foram fotografados em MEV e ilustrados na Figura 2.

Os foraminíferos bentônicos foram classificados em nível genérico, totalizando 56 táxons. O maior número de superfamílias (total de 13) foi observado na subordem Rotaliina, com táxons de 25 famílias e 31 gêneros. A maioria dessas famílias está representada por apenas um gênero. $\mathrm{Na}$ Figura 3 são ilustrados os gêneros de foraminíferos bentônicos mais frequentes.

\section{Bioestratigrafia}

A distribuição estratigráfica das principais espécies de foraminíferos planctônicos utilizadas para a caracterização de biozonas no intervalo 858-642 m encontra-se na tabela 1 . Foram identificadas as biozonas 'Globigerinoides' higginsi (F-340), Orbulinoides beckmanni (F-350) e Acarinina rohri (F-360), segundo o arcabouço biocronoestratigráfico de Noguti \& Santos (1972). Essas biozonas posicionam cronoestratigraficamente os depósitos do intervalo estudado no Eoceno médio (Figura 4).

O topo da biozona F-340 foi identificado no poço a $705 \mathrm{~m}$ de profundidade pela última ocorrência da espécie nominativa 'Globigerinoides' higginsi (= Guembelitrioides nuttalli segundo Pearson et al., 2006). A biozona F-350, cujo topo foi marcado com incerteza na profundidade de $678 \mathrm{~m}$, foi caracterizada pela última ocorrência da espécie Acarinina bullbrooki, uma vez que a espécie-guia da zona, Orbulinoides beckmanni, não foi recuperada. A inferência da biozona F-350 tem como base os níveis de extinção muito próximos dessas duas espécies. O topo da biozona F-360, Truncorotaloides rohri (= Acarinina rohri segundo Berggren et al., 2006) foi marcado a $540 \mathrm{~m}$ de profundidade (Tabela 1; Figura 4).

As três biozonas supracitadas de Noguti \& Santos (1972) foram correlacionadas com as biozonas dos arcabouços bioestratigráficos de foraminíferos planctônicos de Berggren et al. (1995) e Berggren \& Pearson (2005) (Tabela 1). Assim, a zona F-340 possui equivalência com o conjunto das zonas P10? a P12, e também com as zonas E8? a E10. Por outro lado, a zona F-350 se correlaciona estratigraficamente com parte da zona P12 e com a zona E11. Por último, a zona F-360 tem correspondência cronoestratigráfica com o grupo de biozonas P14/P13 e E13/E12 (Tabela 1; Figura 4).

As biozonas de foraminíferos planctônicos, acima mencionadas, foram incluídas no arcabouço bioestratigráfico integrado (Figura 4) do poço SE-2 apresentado em Ferreira (2004). Nesse arcabouço é apresentada a correlação entre as zonas de foraminíferos planctônicos, de palinomorfos (miósporos e dinoflagelados) e de nanofósseis calcários propostos tanto para bacias brasileiras (zonas locais) como em zoneamentos internacionais.

\section{Principais grupos de foraminíferos}

Os foraminíferos foram reunidos em grupos, sendo reconhecidos táxons planctônicos e bentônicos em toda seção paleocênica-eocênica do Baixo de Mosqueiro (Ferreira, 2004). Com base na variação dos componentes nas associações de foraminíferos e de suas abundâncias foi possível interpretar as condições da evolução paleobatimétrica e paleoambiental na área do Baixo de Mosqueiro (Ferreira, 2004). Essa evolução paleobatimétrica pode ser observada no poço SE-2, onde a condição batial superior/nerítico profundo encontrada na base do intervalo passa para condição nerítico raso no topo (Figura 4).

Nas Figuras 5-7 são apresentados os padrões de distribuição das abundâncias relativas dos diferentes elementos composicionais e dos diferentes grupos de foraminíferos do intervalo Eoceno médio do poço SE-2. A Figura 5 mostra as relações entre as abundâncias de foraminíferos planctônicos e bentônicos e entre os bentônicos epifaunais e infaunais. Pode-se observar também a relação entre as abundâncias dos foraminíferos bentônicos separados pelo tipo de carapaça (aglutinantes: AGL; porcelanosos: P; calcário-hialinos: CH), 

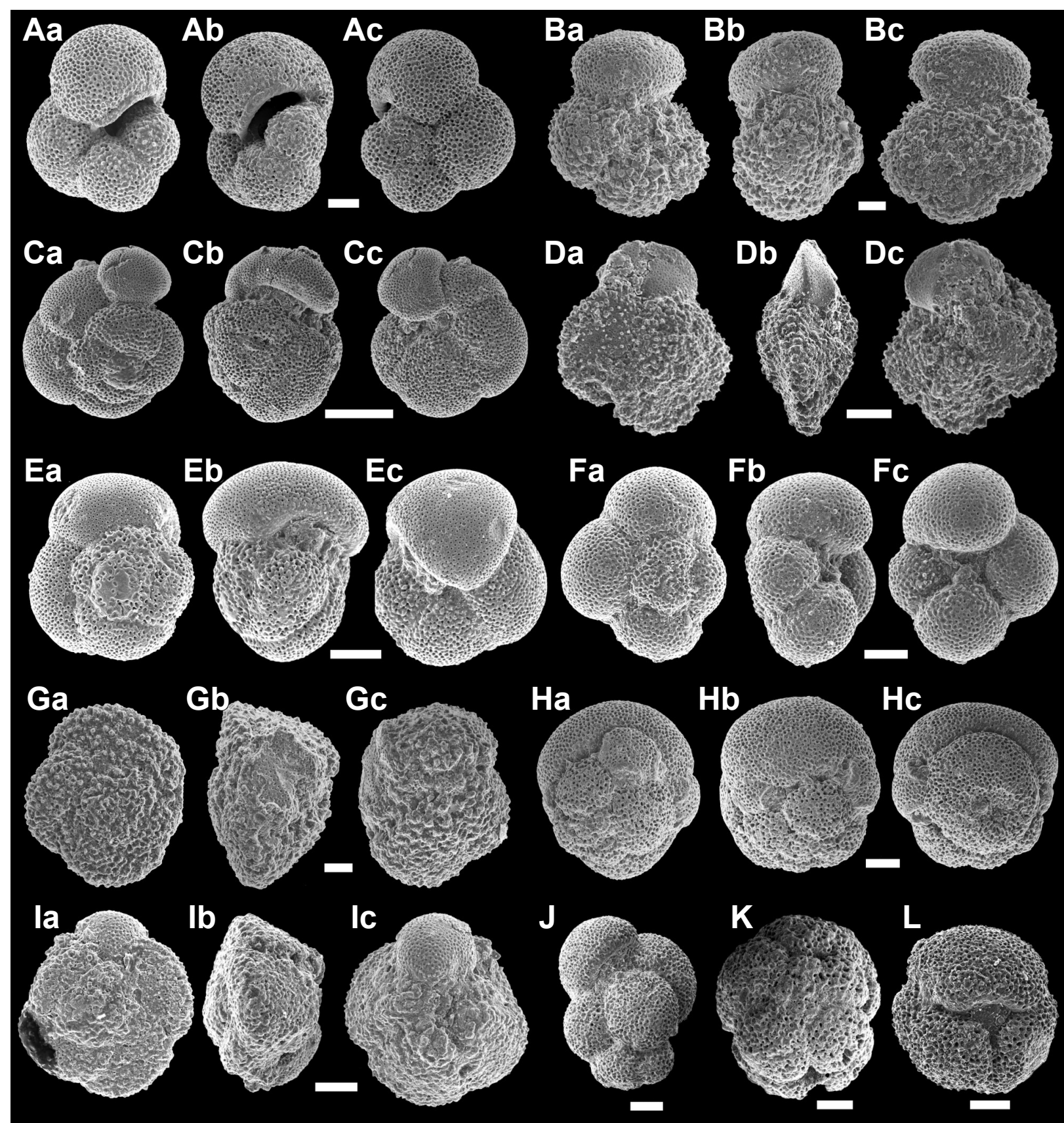

Figura/Figure 2. Fotomicrografias em MEV de espécies de foraminíferos planctônicos do poço SE-2. / SEM photomicrographies of planktonic foraminifera species of the well SE-2. A(a-c), Paragloborotalia griffinae, prof./depth $705 \mathrm{~m}$. B(a-c), Acarinina rohri, prof./depth $846 \mathrm{~m}$. C(a-c), Turborotalia altispiroides, prof./depth $660 \mathrm{~m}$. D(a-c), Morozovelloides bandyi, prof./depth $705 \mathrm{~m}$. E(a-c), Turborotalia increbescens, prof./ depth 705 m. F(a-c), Subbotina hagni, prof./depth 705 m. G(a-c), Acarinina bullbrooki, prof. 846 m. H(a-c), Globigerinatheka barri, prof./depth $660 \mathrm{~m}$. I(a-c), Acarinina punctocarinata, prof./depth $705 \mathrm{~m}$. J, Guembelitrioides nuttalli, prof./depth $846 \mathrm{~m}$. K, Globigerinatheka sp., prof./depth $678 \mathrm{~m}$. L, Globigerinatheka sp., prof./depth $705 \mathrm{~m}$. Escalas/Scale bars: A, D-F, H, I, K, L = $100 \mu \mathrm{m} ; \mathrm{B}, \mathrm{G}=60 \mu \mathrm{m} ; \mathrm{J}=80 \mu \mathrm{m} ; \mathrm{C}=200 \mu \mathrm{m}$.

com os bentônicos $\mathrm{CH}$ remobilizados (macroforaminíferos) e com as abundâncias relativas dos gêneros mais representativos dos macroforaminíferos.

Na Figura 5A é mostrada a relação entre as curvas das abundâncias relativas dos foraminíferos planctônicos e bentônicos. Os percentuais do primeiro grupo aumentam progressivamente (de 6 a 69\%) nas porções inferior e média do intervalo, enquanto os percentuais dos bentônicos decrescem. Esse resultado sugere para essas porções uma fase transgressiva. Entretanto, a partir da profundidade $714 \mathrm{~m}$ em direção ao topo, os percentuais dos planctônicos sofrem uma forte redução. Nessa porção, os bentônicos dominam as associações (60-85\%) permitindo interpretar que a sedimentação ocorreu durante uma fase regressiva.

As curvas das abundâncias relativas dos bentônicos epifaunais e infaunais mostram-se divergentes na maior parte do intervalo (Figura 5B). Os percentuais dos foraminíferos infaunais aumentam $(20-50 \%)$ da base até a profundidade 

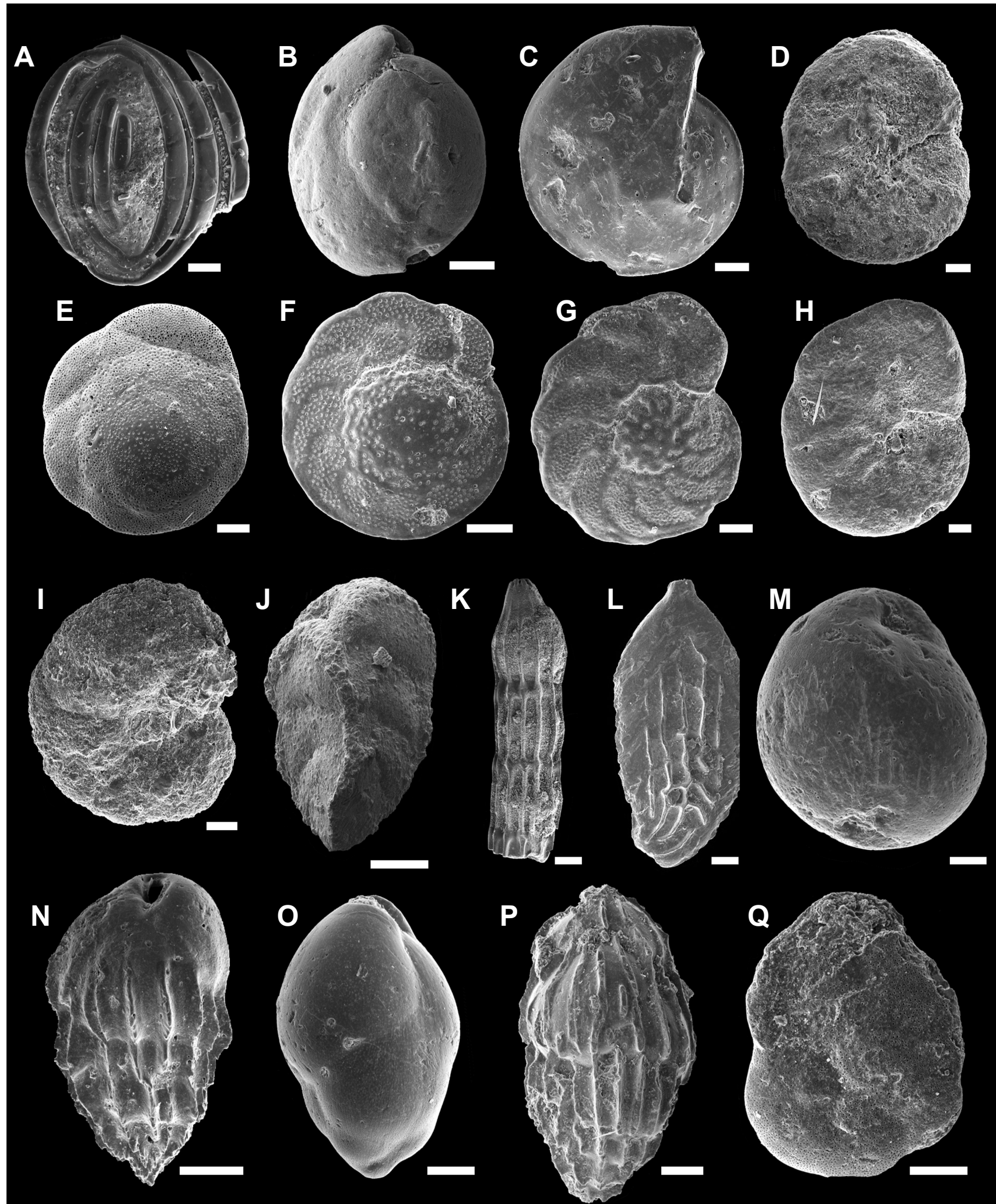

Figura/Figure 3. Fotomicrografias em MEV de gêneros de foraminíferos bentônicos do poço SE-2. / SEM photomicrographies of benthonic foraminifera genera of the well SE-2. Abreviaturas morfológicas/Morphological abbreviations: VL: vista lateral/lateral view; VU: vista umbilical/ umbilical view; VE: vista espiral/spiral view. A, B, Porcelanosos. C-H, K-Q, Calcário-hialinos. I, J, Aglutinantes. A, Spiroloculina, VL, prof./depth 705 m. B, Quinqueloculina, VL, prof./depth 660 m. C, Lenticulina, VL, prof./depth 696 m. D, Cibicorbis, VU, prof./depth 846 m. E, Eponides, VE, prof./ depth 726 m. F, Cibicidoides, VE, prof./depth 678 m. G, Planulina, VE, prof./depth 696 m. H, Cibicides, VU, prof./depth 642 m. I, Haplophragmoides, VU, prof./depth 726 m. J, Gaudryina, VL, prof./depth 696 m. K, Pyramidulina, VL, prof./depth 696 m. L, Palmula, VL, prof./depth 705 m. M, Globocassidulina, VL, prof./depth $846 \mathrm{~m}$. N, Bulimina, VL, prof./depth $846 \mathrm{~m}$. O, Globobulimina, VL, prof./depth $834 \mathrm{~m}$. P, Uvigerina, VL, prof./ depth 642 m. Q, Cancris, VE, prof./depth $822 \mathrm{~m}$. Escalas/Scale bars: A, D, H, M = $40 \mu \mathrm{m} ; \mathrm{B}, \mathrm{C}, \mathrm{E}-\mathrm{G}, \mathrm{O}-\mathrm{Q}=100 \mu \mathrm{m} ; \mathrm{I}-\mathrm{L}, \mathrm{N}=200 \mu \mathrm{m}$. 
Tabela 1. Distribuição estratigráfica das principais espécies de foraminíferos planctônicos e biozonas interpretadas. Arcabouços bioestratigráficos de (1) Noguti \& Santos (1972), (2) Berggren et al. (1995), e (3) Berggren \& Pearson (2005). Em negrito as espécies índices.

Table 1. Stratigraphic distribution chart of the main planktonic foraminifera species and the biozones interpretated. Biostratigraphic frameworks by (1) Noguti \& Santos (1972), (2) Berggren et al. (1995), and (3) Berggren \& Pearson (2005). In bold the index species.

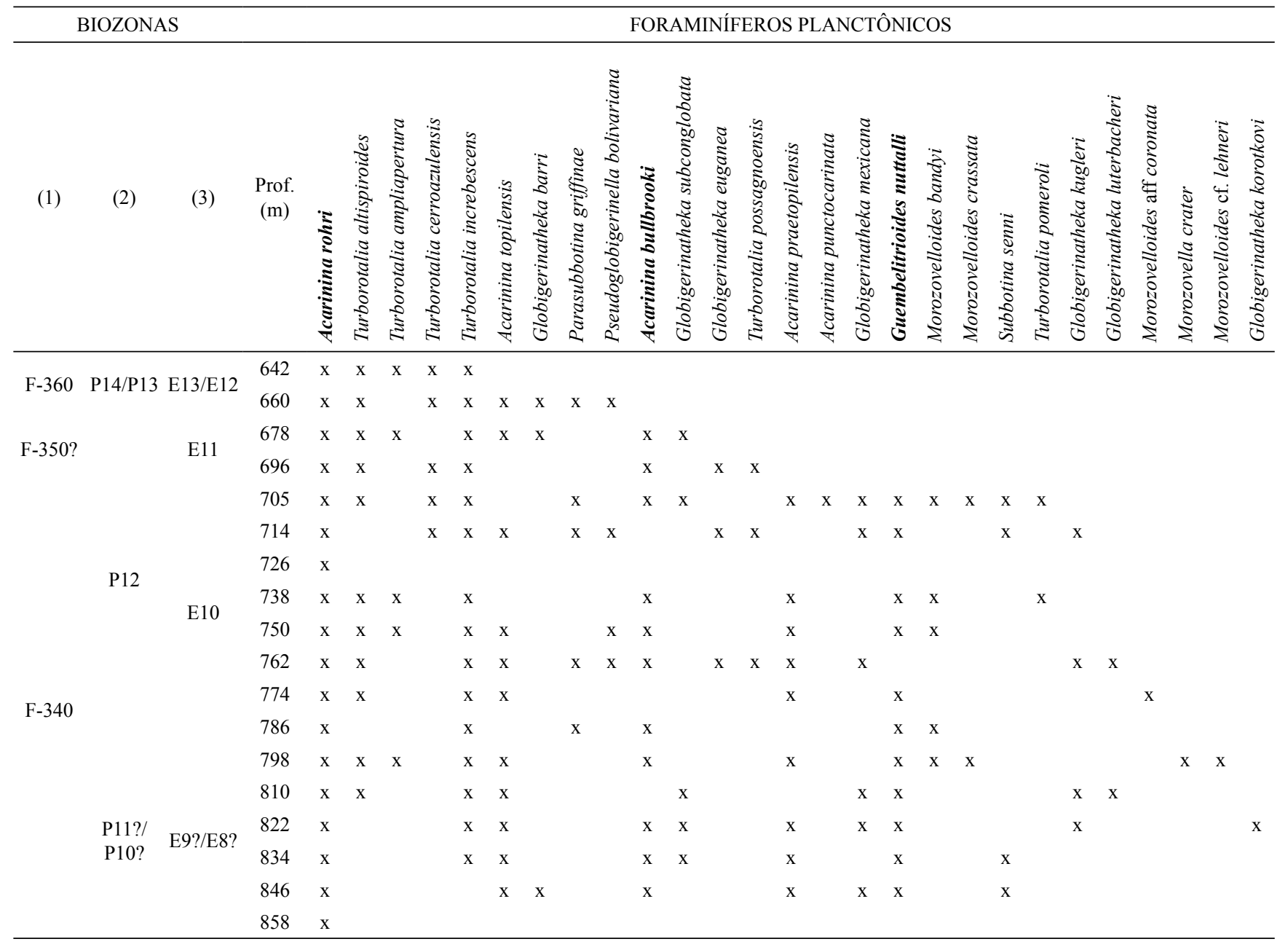

de $750 \mathrm{~m}$, enquanto os epifaunais sofrem um decréscimo de seus percentuais (80-40\%). A partir desse nível, os epifaunais dominam as associações (60-80\%) e suas abundâncias reduzem em direção ao topo (45\%), quando os infaunais atingem até $50 \%$ da associação. Na porção média do intervalo, os percentuais dos infaunais e epifaunais são próximos, em torno de $55 \%$.

Segundo Ortiz \& Thomas (2006), o aumento da abundância dos bentônicos infaunais está relacionado a fases de maior produtividade orgânica e, provavelmente, a uma redução nos níveis de oxigenação do substrato, sendo essas interpretações admitidas também para o intervalo do Eoceno médio do poço SE-2. Para Koutsoukos \& Hart (1990), o aumento dos percentuais dos foraminíferos infaunais pode também estar relacionado à restrição do nicho ecológico em virtude do aumento da lâmina d'água. Os padrões de distribuição das abundâncias dos bentônicos infaunais têm uma relação positiva com a curva do total de foraminíferos planctônicos e, os bentônicos epifaunais, com a curva do total de foraminíferos bentônicos.
Entre os foraminíferos bentônicos foram registrados táxons com parede de composição diferente: aglutinantes, porcelanosa e calcários-hialinos (Figura 5C). $\mathrm{O}$ grupo dos bentônicos de carapaças aglutinantes está presente na maioria das amostras e tem seus percentuais mais significativos $(<15 \%)$ na parte média do intervalo. Os gêneros identificados foram Gaudryina, Haplophragmoides, Reticulophragmium, Spiroplectammina, Textularia e Vulvulina. Os bentônicos de parede porcelanosa (Pyrgo, Quinqueloculina e Spiroloculina) ocorrem em quase todo intervalo e apresentam percentuais mais significativos na parte média e superior do mesmo, atingindo até $20 \%$. Os bentônicos calcário-hialinos, bem diversificados, predominam nas associações, com percentuais que variam entre 40-95\%. Foram identificados 43 gêneros: Alabamina, Allomorphina, Baggina, Bulimina, Cancris, Cibicides, Cibicidoides, Cibicorbis, Dentalina, Ellipsosdimorphina, Eponides, Globobulimina, Globocassidulina, Globulina, Gyroidinoides, Hanzawaia, Helicostegina, Hoeglundina, Laevidentalina, Lagena, Lagenoglandulina, Lenticulina, Loisthostomata, Marginulina, Marginulipnosis, Nodosaria, 


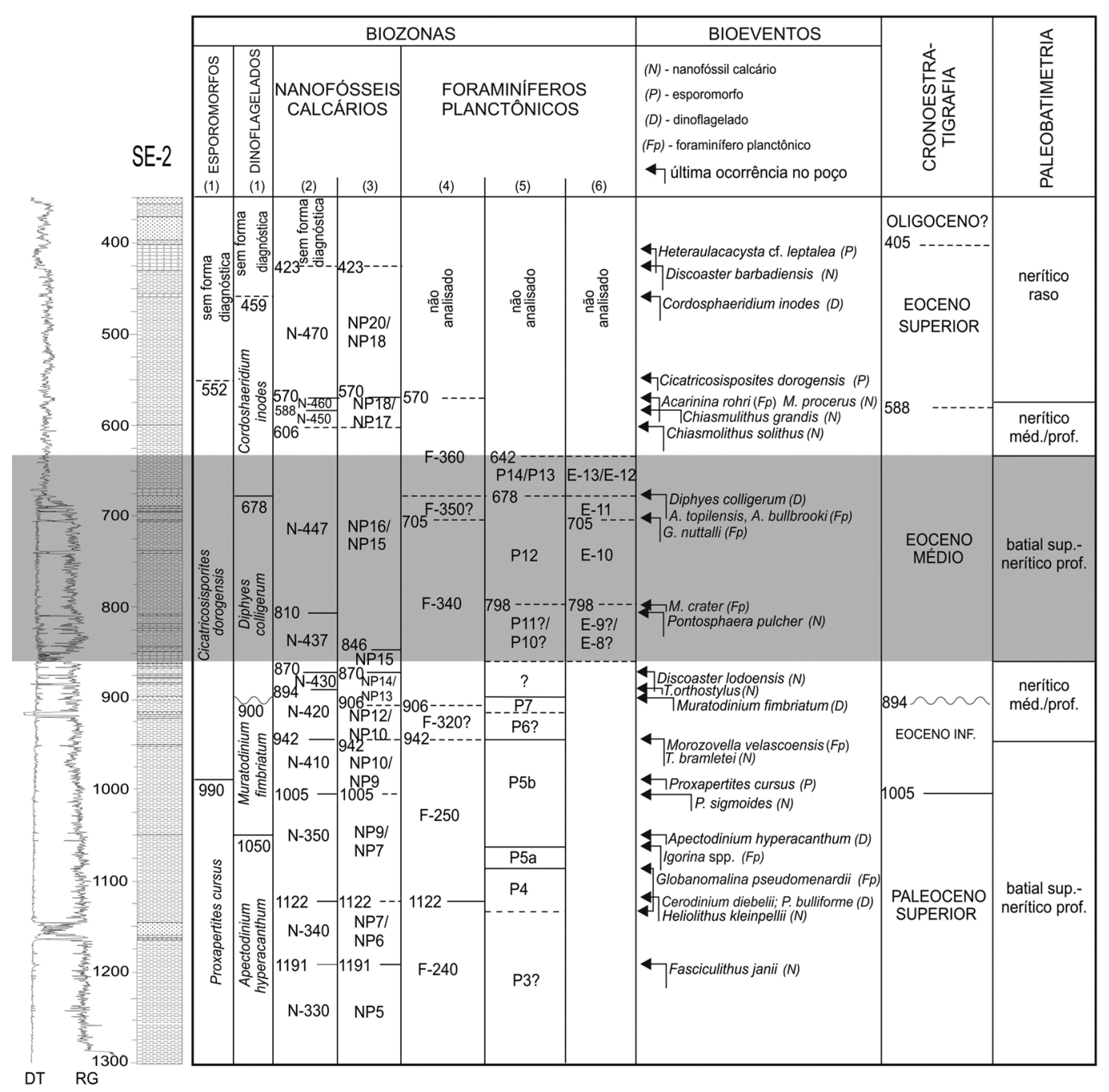

Figura/Figure 4. Biozonas, cronoestratigrafia e condições paleobatimétricas reconhecidas no poço SE-2 (modificado de Ferreira, 2004). / Biozones, chronoestratigraphy and paleobathymetric conditions identified in the well SE-2 (modified from Ferreira, 2004). Indicadores numéricos/Numerical indicators: (1) Ferreira (2004); (2) Antunes et al. (1998); (3) Martin (1971); (4) Noguti \& Santos (1972); (5) Berggren et al. (1995); (6) Berggren \& Pearson (2005).

Nuttallides, Oridorsalis, Osangularia, Palmula, Planulina, Praeglobobulimina, Pseudonodosaria, Pullenia, Pyramidulina, Reticulopalmula, Saracenaria, Siphonina, Siphonodosaria, Sphaeroidina, Uvigerina, Vaginulina e Valvulineria.

Um grupo de bentônicos calcário-hialinos (macroforaminíferos), típico de ambientes neríticos rasos, foi registrado em todo intervalo estudado e considerados como elementos remobilizados (CH-R, Figuras 5C,D). Esse grupo está representado pelos gêneros Helicostegina (dominante) e Miogypsina, Nummulites, Archaias, Civrieuxia, Helicostegina e Amphistegina, com ocorrências esporádicas, mas relativamente abundantes. O maior percentual de macroforaminíferos remobilizados encontrase na base do intervalo, perfazendo $40 \%$ dos calcárioshialinos, com Helicostegina dominando a associação e com Nummulites, Civrieuxia, e Amphistegina subordinados. Outros dois picos de menor intensidade foram observados: um na profundidade $738 \mathrm{~m}$, com a presença apenas de
Helicostegina $(<10 \%$ dos $\mathrm{CH})$, e outro na profundidade $705 \mathrm{~m}$, com Helicostegina $(20 \%$ dos $\mathrm{CH})$ dominando a associação e Civrieuxia e Miogypsina pobremente representados (Figura 5D).

\section{Padrão de distribuição dos gêneros de foraminíferos ben- tônicos calcário-hialinos}

A distribuição estratigráfica dos táxons calcário-hialinos (Figura 6) mostra que o gênero Lenticulina é o mais representativo em quase todo intervalo (20-70\%). Além desse gênero, três outros apresentam percentuais elevados (20-40\%) somente em alguns intervalos: Eponides (porção inferior), Globobulimina (porção média) e Bulimina (porção superior). Esses dados permitem interpretar alta produtividade orgânica no meio. Entre os gêneros calcário-hialinos também com percentuais significativos, porém em menor proporção ( $<20 \%)$, estão Cibicidoides, Planulina, Pyramidulina, Hoeglundina, Uvigerina e Palmula. 


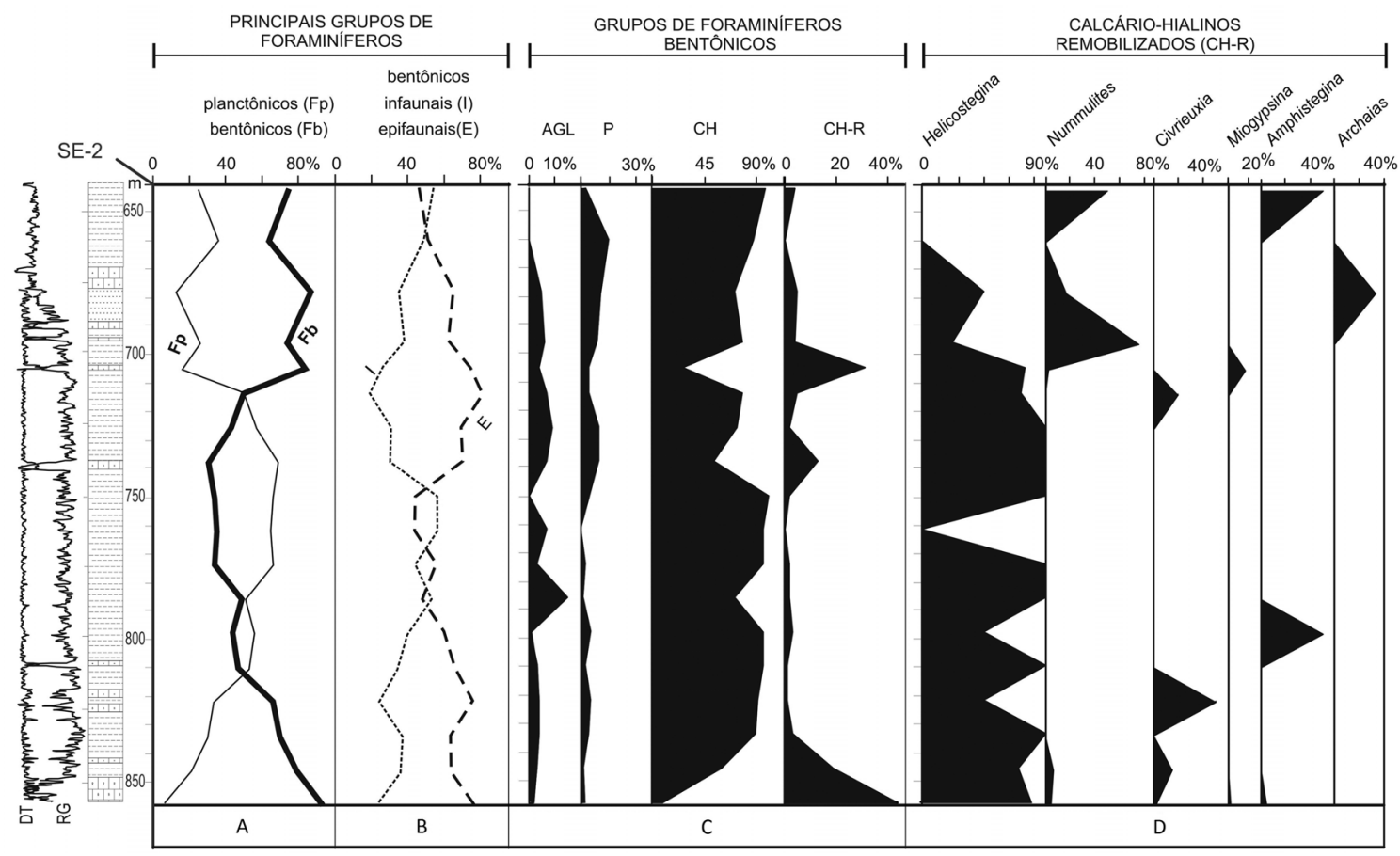

Figura 5. Abundância relativa (\%) dos foraminíferos do intervalo em estudo. Abreviaturas: AGL, bentônicos aglutinantes; P, bentônicos porcelanosos; $\mathbf{C H}$, bentônicos calcário-hialinos; $\mathbf{C H}-\mathbf{R}$, bentônicos calcário-hialinos remobilizados (macroforaminíferos).

Figure 5. Relative abundance (\%) of foraminifers in the studied interval. Abbreviations: AGL, agglutinated foraminifera; $\mathbf{P}$, porcelanaceous foraminifera; $\mathbf{C H}$, calcareous-hyaline foraminifera; $\mathbf{C H}-\mathbf{R}$, remobilized calcareous-hyaline foraminifera (large foraminifera).

Na Figura 6 é apresentada a curva de diversidade dos bentônicos calcário-hialinos, construída a partir do total de número de táxons. A curva apresenta variações dos valores na porção inferior do intervalo e torna-se mais regular na porção superior, onde há um número maior de gêneros, mas ocorrem em baixos percentuais. Essa partição corresponde à mudança de uma fase transgressiva para uma regressiva, conforme evidenciado pela tendência das variações paleobatimétricas mostradas na Figura 4.

Os picos de diversidade (Figura 6, $d 1-d 5$ ) correspondem com associações dominadas por diferentes grupos de bentônicos. O pico $d l$ corresponde à abundância de Eponides $(<30 \%)$ e macroforaminíferos (Figura $5 \mathrm{C}$ ). O pico $d 2$, o mais expressivo de todos, corresponde a uma associação dominada por Eponides, Lenticulina e Bulimina. O pico d3 caracteriza uma associação dominada por Lenticulina (40\%), Bulimina (20\%) e Globobulimina ( $<15 \%)$. O pico $d 4$ corresponde a uma associação dominada por Globobulimina $(40 \%)$ associada a Bulimina e Planulina. No pico $d 5$, porção superior do intervalo, ocorre uma associação dominada por Lenticulina (alcançando 60\%) e maior variedade de gêneros, entre eles Planulina, Hoeglundina, Uvigerina e Palmula com abundâncias não ultrapassando $20 \%$ da associação.

\section{Morfogrupos funcionais de foraminíferos bentônicos}

$\mathrm{O}$ estudo detalhado das associações de foraminíferos bentônicos do intervalo 858-642 $\mathrm{m}$ do poço SE-2 (Eoceno médio) mostrou que a maioria dos morfogrupos funcionais definidos por Koutsoukos \& Hart (1990) e Costa (2004), na seção cretácica das bacias Sergipe e Ceará, podem ser reconhecidos em depósitos mais novos.

Na seção eocênica da bacia de Sergipe foram reconhecidos 13 morfogrupos, cuja nomenclatura segue aquela estabelecida por Koutsoukos \& Hart (1990). O maior número de morfogrupos foi registrado entre os foraminíferos calcário-hialinos: CH-A.2, CH-A.3, CH-A.4, CH-A.5, CH-A.6, CH-B.1, CH-B.2, CH-B.3 e CH-B.4. Dentre eles, os mais representativos no intervalo estudado são CH-A.6, CH-B.4 e CH-A.5 (Figura 7).

No morfogrupo CH-A.6, os táxons possuem carapaça lenticular, planispiralada, periferia subaguda/carenada. O morfogrupo CH-A.6 é constituído por formas bentônicas de hábito preferencialmente epifaunal. São táxons representados pelos gêneros Lenticulina, Saracenaria e Siphonina. Este morfogrupo está representado principalmente pelo gênero Lenticulina, com abundância variando de 20 a $60 \%$ na associação bentônica calcário-hialina, sendo mais abundante na porção superior do intervalo. Tais foraminíferos ocupam áreas localizadas próximas à borda da plataforma e do talude superior, adaptando-se às mais variadas condições ambientais.

O morfogrupo CH-B.4 é constituído por táxons com carapaça alongada, afunilada e em seção transversal é circular a oval. São bentônicos infaunais. No intervalo em estudo, a associação que integra o morfogrupo é constituída pelos gêneros Bulimina, Globobulimina, Praeglobobulimina e Uvigerina. Na porção inferior do intervalo (Figura 7), os percentuais de CH-B.4 aumentam progressivamente até $748 \mathrm{~m}$, ultrapassando $40 \%$ dos bentônicos calcário-hialinos. Porém, seus percentuais caem bruscamente a partir de $748 \mathrm{~m}$, 


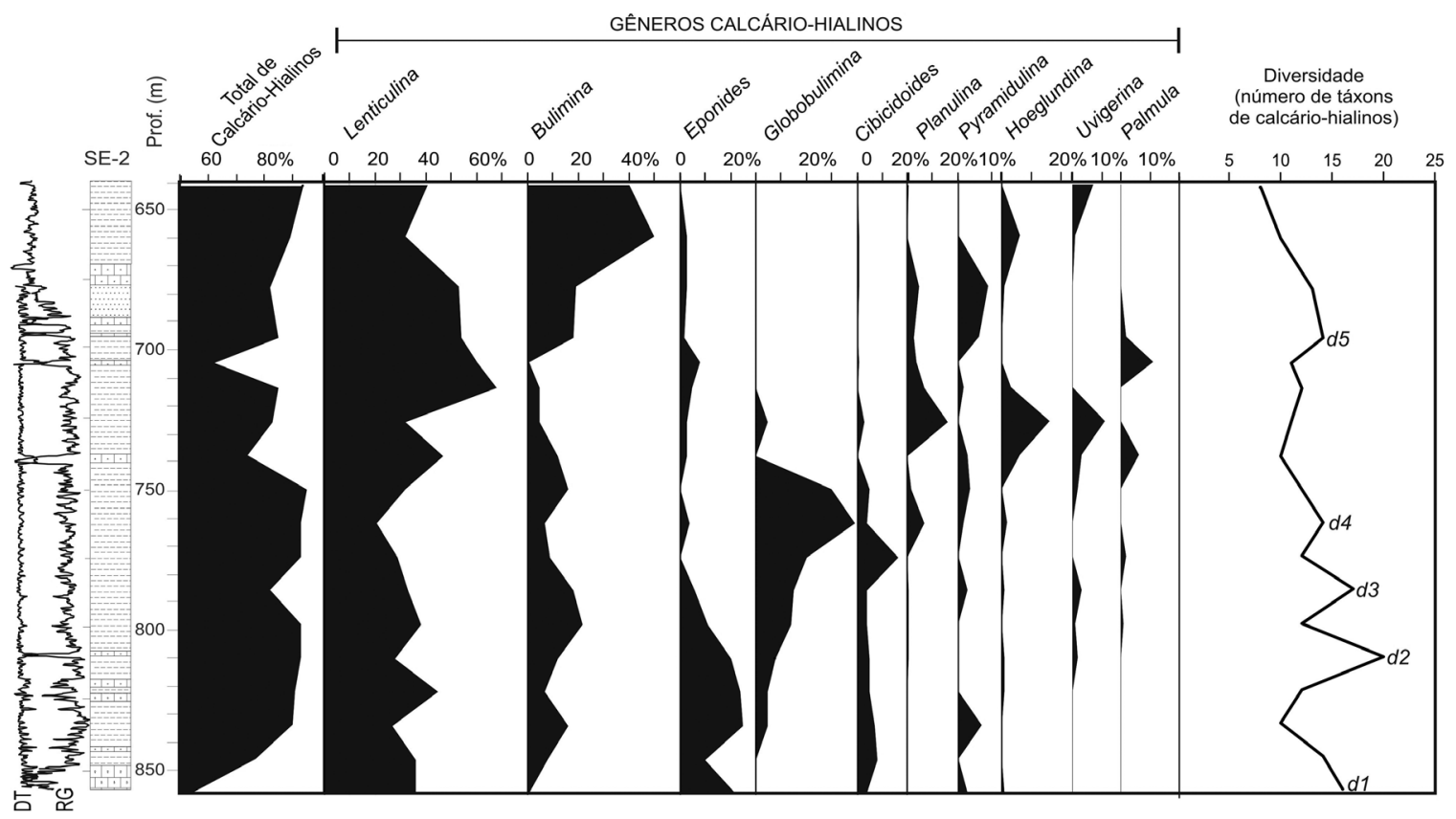

Figura 6. Abundância relativa (\%) e curva de diversidade dos foraminíferos calcário-hialinos. Os principais picos de diversidade estão marcados de $d 1$ a $d 5$.

Figure 6. Relative abundance and diversity curve of calcareous-hiyaline foraminifera. The main pick of diversity are marked from $\mathbf{d} \mathbf{1}$ to $\mathbf{d 5 .}$

e apenas na porção superior, o morfogrupo CH-B.4 volta a alcançar percentuais acima de $40 \%$. Os táxons que compõem o morfogrupo CH-B.4 mostram um relação inversa com o morfogrupo CH-A.6.

De acordo com os estudos realizados por Ortiz \& Thomas (2006) na seção eocena Fortuna, situada no sudeste da Espanha, há uma correlação positiva entre os grupos infaunais, o fluxo de carbono orgânico e a produtividade do meio. Segundo aquelas autoras, os picos de maior frequência do gênero Globobulimina poderiam estar associados a um aumento no influxo de matéria orgânica no paleoambiente, que seria a fonte de alimentação destes organismos de hábitos infaunais.

O morfogrupo CH-A.5 é composto por táxons com carapaça trocoespiral baixa a quase planispiral, comprimida, quase lenticular; periferia subaguda a carenada. São bentônicos epifaunais. No intervalo estudado foram encontrados espécimes dos gêneros Cibicidoides, Eponides, Hanzawaia, Hoeglundina, Loisthostomata, Oridorsalis, Osangularia e Planulina.

Os morfogrupos CH-A.3, CH-B.1, CH-B.2, CH-B.3, apesar dos baixos percentuais $(<10 \%)$, são ainda significativos na associação (Figura 7). No morfogrupo CH-A.3 estão incluídos foraminíferos com a morfologia da carapaça trocoespiral baixa à planispiral inflada, biconvexa e periferia arredondada. $\mathrm{O}$ morfogrupo está representado por Cancris e Pullenia. O morfogrupo CH-A.3 inclui foraminíferos epifaunais e infaunais e está presente na porção mais inferior do intervalo (Figura 7).

Os espécimes que compõem o morfogrupo $\mathrm{CH}-\mathrm{B} .1$ apresentam carapaça globosa/oval e alongada/fusiforme e são foraminíferos bentônicos de hábito epifaunal/infaunal. O morfogrupo CH-B.1 está melhor representado na porção inferior do intervalo com ocorrência dos gêneros Allomorphina, Ellipsodimorphina, Globocassidulina, Globulina, Lagena, Lagenoglandulina e Sphaeroidina. (Figura 7).

Os foraminíferos incluídos no morfogrupo CH-B.2 possuem a carapaça palmar, comprimida, planispiralada a unisserial, representados pelos gêneros Palmula, Reticulopalmula e Vaginulina. Os táxons fazem parte do grupo dos bentônicos de hábitos epifaunal/infaunal. Os percentuais mais significativos do morfogrupo CH-B.2 (5-10\%) encontram-se aproximadamente na porção médiasuperior do intervalo (Figura 7).

As carapaças dos foraminíferos do morfogrupo CH-B.3 são alongadas, retas a arqueadas, unisserial ou planispiral/uniserial e esses bentônicos têm hábitos epifaunais e infaunais. $\mathrm{O}$ grupo CH-B.3 está presente na maioria das amostras, porém sua maior representatividade encontra-se nas porções inferior e superior do intervalo (Figura 7). Os gêneros presentes são Dentalina, Laevidentalina, Marginulina, Marginulinopsis, Nodosaria, Pseudonodosaria, Pyramidulina e Siphonodosaria.

Os morfogrupos CH-A.2 e CH-A.4 apresentam baixos percentuais $(<1 \%)$, estando esses bentônicos calcáriohialinos representados por táxons dos gêneros Baggina, Cibicorbis, Valvulineria, Alabamina, Cibicides, Gyroidinoides e Nuttallides.

Os táxons do morfogrupo $\mathrm{CP}$ (subgrupos $\mathrm{CP}-\mathrm{A}$ e $\mathrm{CP}$ B), contendo formas porcelanosas, apresentam carapaça alongada a oval. Esses bentônicos são de hábito epifaunal/ infaunal raso. O morfogrupo CP-B $(<10 \%)$ (Figura 7$)$ é mais representativo nas porções média e superior do intervalo e 
está representado por táxons de Pyrgo e Quinqueloculina. Os táxons representantes do morfogrupo CP-A $(<1 \%)$ pertencem a Spiriloculina.

Entre os foraminíferos aglutinantes foram reconhecidas carapaças dos morfogrupos AG-B.2 e AG-A, que possuem carapaça espiral a trocoespiral baixa/planispiral, inflada, periferia arredondada e são organismos de hábito epifaunal-infaunal. Os táxons reconhecidos no morfogrupo AG-B.2 pertencem aos gêneros Haplophragmoides e Reticulophragmium e são mais significativos $(<10 \%)$ na porção média do intervalo (Figura 7). O morfogrupo AG-A está representando pelos gêneros Gaudryina, Textularia e Vulvulina, e seus percentuais são baixos $(<1 \%)$.

\section{PALINOMORFOS DO INTERVALO PALEOCENO SUPERIOR-EOCENO SUPERIOR DO POÇO SE-2}

A evolução paleobatimétrica caracterizada no intervalo do Paleoceno ao Eoceno do poço SE-2, com base na variação composicional das associações de foraminíferos bentônicos, indicou águas profundas na porção inferior passando para águas rasas na superior (Figura 4). Essa informação é corroborada pelo aumento dos percentuais dos palinomorfos continentais (esporos, grãos de pólen e representantes de algas clorófitas, em especial, Pediastrum) em direção ao topo do intervalo (Figura 8). Com base nos dados quantitativos foi possível sugerir uma fase transgressiva para o intervalo Paleoceno-Eoceno inferior e uma regressiva para o Eoceno médio-superior (Figuras 4, 8, 9).
No intervalo Paleoceno-Eoceno inferior do poço em estudo, composto predominantemente por pelitos e esporádicas entradas de areias, foi recuperada uma rica associação palinológica com domínio dos elementos marinhos (dinoflagelados e palinoforaminíferos) sobre os continentais (Figura 8). Os dinoflagelados pertencentes aos gêneros Apectodinium, Glaphyrocysta e Homotryblium são os componentes marinhos mais significativos (Figuras 8, 9).

Os eventos de abundância dos dinoflagelados termófilos Glaphyrocysta e Apectodinium são indicadores de condições de águas quentes para o período (Köthe, 1990; Knox, 1996; Ferreira, 2004; Ferreira et al., 2006). Destaca-se ainda que a abundância de Apectodinium vem sendo usada como resposta ao evento de aquecimento global PETM ocorrido no final do Paleoceno (Kennett \& Stott, 1991; Crouch et al., 2001, 2003; Sluijs et al., 2005, Vandenberghe et al., 2012).

Associada às abundâncias relativas do dinoflagelado Apectodinium na área em estudo encontram-se as últimas ocorrências de um grupo de foraminíferos bentônicos remanescentes do Cretáceo (Figura 9), aqui atribuídas às mudanças ambientais ocorridas próximas ao substrato (Viviers \& Ferreira, 2006a,b). Esse conjunto de bioeventos de foraminífero vem sendo usado para caracterizar o evento global de aquecimento de fundo (Benthic Foraminiferal Extinction Event-BFEE) ocorrido ao final do Paleoceno (Thomas \& Shackleton, 1996; Vandenberghe et al., 2012). A interpretação da ocorrência de tendência de aquecimento é reforçada pelos resultados das análises de $\delta^{18} \mathrm{O}$ e $\delta^{13} \mathrm{C}$ (Ferreira, 2004) (Figura 8). O registro dos eventos acima referidos sugere presença de águas marinhas quentes durante

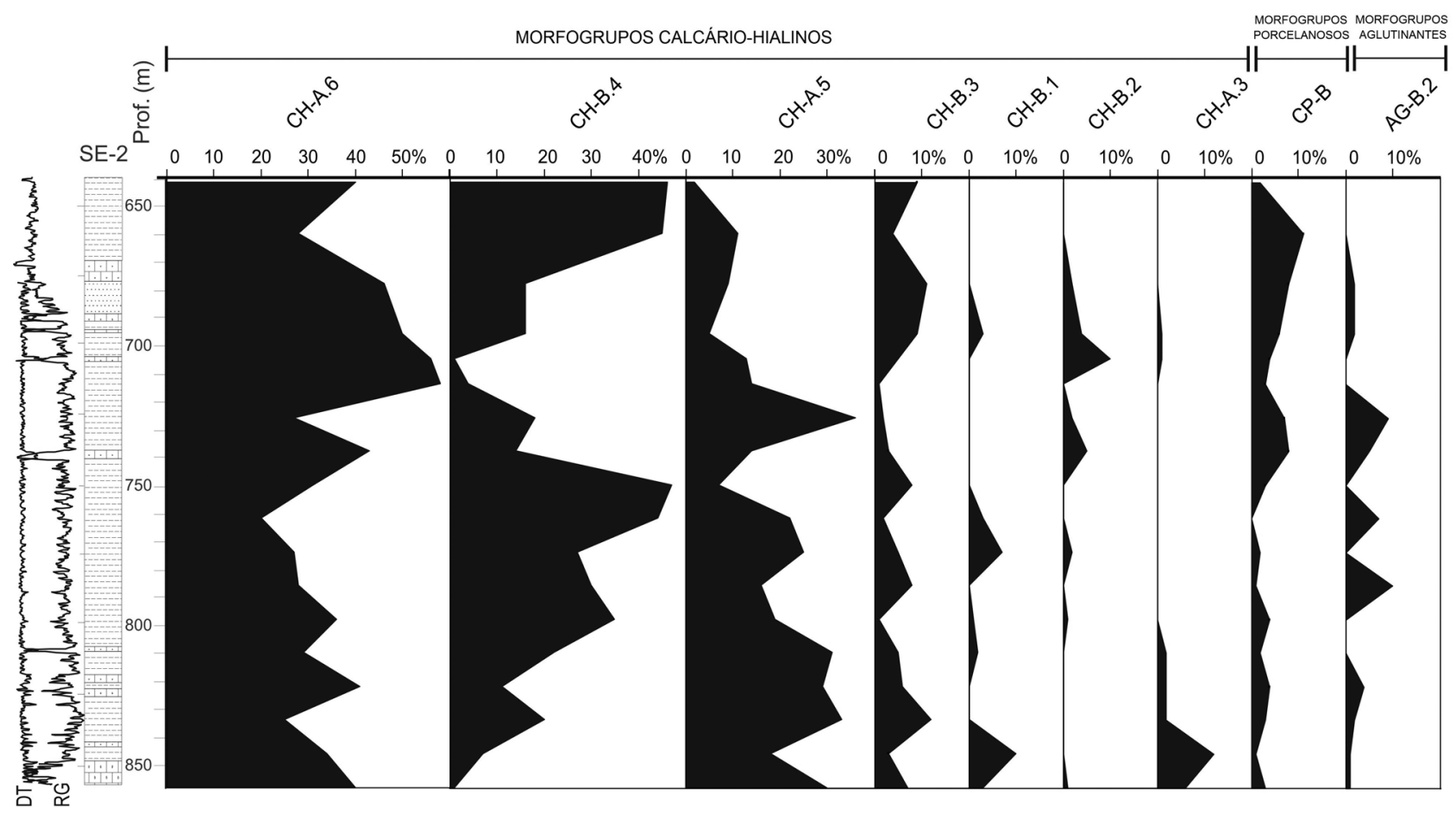

Figura 7. Padrão de distribuição da abundância relativa (\%) dos morfogrupos de foraminíferos bentônicos no intervalo estudado.

Figure 7. Relative abundance of calcareous-hyaline morphogroup in the studied interval. 
a deposição dos sedimentos paleocênicos e eoeocênicos e de mudanças nas condições das águas de fundo no sítio deposicional.

No intervalo do Eoceno médio-superior do poço SE-2, que contém uma litologia variegada (pelitos intercalados com pacotes de arenitos e/ou calcarenitos), observou-se uma mudança dos componentes das associações palinológicas. Os dinoflagelados continuam a predominar nas associações, porém destacam-se os táxons dos gêneros Operculodinium, Homotryblium e Spiniferites. Por outro lado, os percentuais dos palinomorfos continentais aumentam em direção ao topo do intervalo (Ferreira, 2004).

Em relação à porção do Eoceno médio, intervalo analisado por foraminíferos no presente estudo, são significativas as abundâncias de Enneadocysta (dinoflagelado) e Tasmanites (prasinofíceas) (Figura 8), palinomorfos marinhos que vêm sendo associados a condições de águas frias (Williams et al., 1990; Guy-Ohlson, 1996; Premaor et al., 2013) e à tendência de resfriamento de caráter global ocorrida no Eo-mesoeoceno (Zachos et al., 1993; Bohaty \& Zachos, 2003). Tais condições são relacionadas às alterações paleoceanográficas e das correntes oceânicas ocorridas no Eoceno devido às aberturas das passagens oceânicas Drake e Tasmânia (Zachos et al., 1993; Sluijs et al., 2003, Vanderberghe et al., 2012).

A tendência de resfriamento durante o Mesoeoceno na costa leste brasileira é sugerida pelo sinal isotópico de oxigênio obtido para os poços JQ-1 e JQ-2, bacia de Jequetinhonha, além do poço SE-2 (Maizatto et al.,
2004), onde os táxons de Enneadocysta e Tasmanites são significativos. Os representantes do gênero Enneadocysta são elementos importantes da "flora Transantartica" endêmica caracterizada por Wrenn \& Beckman (1982).

\section{Palinomorfos vs. Foraminíferos no intervalo Eoceno médio do poço SE-2}

A comparação entre a distribuição estratigráfica das abundâncias relativas dos grupos e morfogrupos de foraminíferos e as abundâncias de palinomorfos do intervalo do Eoceno médio do poço SE-2 mostrou que: (i) na base do intervalo 858-642 m foi registrada uma abundância de macroforaminíferos remobilizados, em especial, Helicostegina (Figura 5), a qual é seguida por abundância de palinomorfos continentais. Estes dados indicam transporte de sedimentos de áreas plataformais rasas e de proveniência continental para o sítio deposicional onde prevalecia condição batial superior-nerítico profundo; (ii) há uma relação direta entre as abundâncias de Enneadocysta (dinoflagelado), Tasmanites (prasinofícea) (Figura 8) e as abundâncias de foraminíferos bentônicos infaunais (Figura 5), evidenciando um favorecimento do desenvolvimento de grupos infaunais devido a mudanças do meio e/ou na disponibilidade de nutrientes (palinomorfos continentais e marinhos); (iii) a abundância de Enneadocysta está relacionada com as abundâncias de Eponides, Bulimina e Pyramidulina, enquanto que a abundância de Tasmanites com as abundâncias de Globobulimina, Bulimina, Cibicidoides e Planulina. Tais

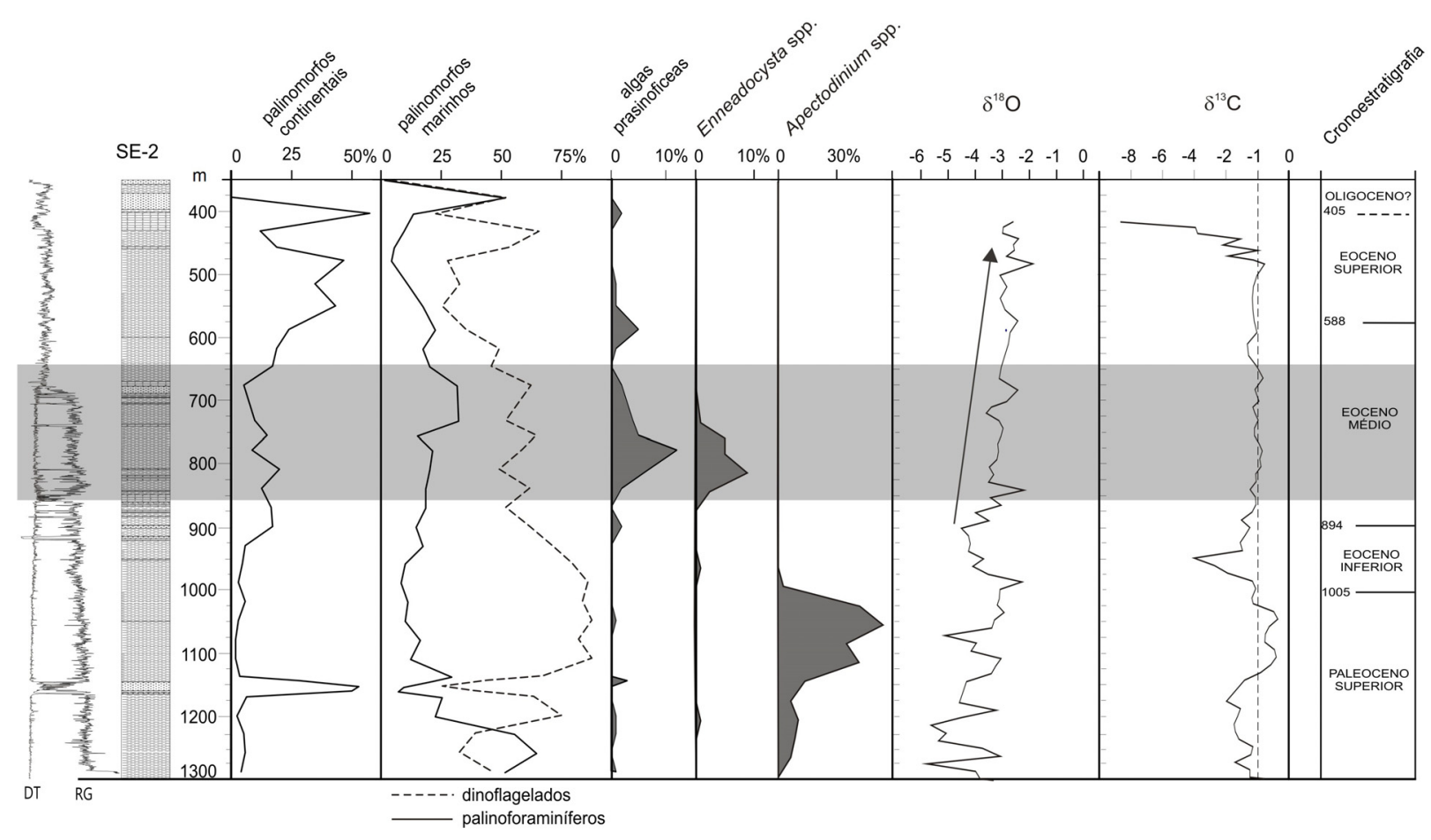

Figura 8. Abundância dos principais grupos de palinomorfos e curvas de isotópos estáveis de oxigênio e carbono do poço SE-2 (segundo Ferreira, 2004). A seta mostra a tendência de resfriamento. Faixa cinza: foco deste estudo.

Figure 8. Relative abundance of the main palynomorph groups and oxygen and carbon stable isotopic curves of the well SE-2 (according to Ferreira, 2004). The arrow shows the cooling trend. Gray area: target of this paper. 
dados permitem interpretar que esses dois palinomorfos marinhos estão relacionados a alta produtividade orgânica e/ou estratificação da coluna d'água num primeiro momento e, em seguida, decorreria uma estabilidade de fundo, sugerida pelos percentuais mais equilibrados dos foraminíferos infaunais e epifaunais; (iv) a grande mudança observada nas curvas de abundâncias de foraminíferos bentônicos e dos palinomorfos continentais e marinhos, na profundidade de $750 \mathrm{~m}$, está sendo associada a um aumento da temperatura da superfície das águas superimposto a tendência de resfriamento. Esta é evidenciada pelas variações dos valores isotópicos (negativo) ocorridos no intervalo correspondente as biozonas de foraminíferos planctônicos E10 e E11 no poço SE-2 (Figuras $2,8)$. Tais mudanças podem estar associadas ao evento de aquecimento de curta duração MECO ocorrido temporalmente entre as passagens das biozonas P12/P13 ou E10-11/E12, do Eoceno médio (Vandenberghe et al., 2012); (v) as condições deposicionais mudam no intervalo Eoceno médio, de transgressiva $(858-738 \mathrm{~m})$ para regressivas $(738-642 \mathrm{~m})$.
São comuns nas associações palinológicas dinoflagelados dos gêneros Operculodinium, Spiniferites, Homotryblium e Lingulodinium. As abundâncias desses palinomorfos marinhos são correlacionáveis às abundâncias dos foraminíferos bentônicos Lenticulina e Bulimina, organismos considerados de rápida adaptação a ambientes estressantes.

\section{CONSIDERAÇÕES FINAIS}

Os resultados da aplicação dos morfogrupos de foraminíferos bentônicos nos estudos paleoambientais são mostrados dentro de um arcabouço bioestratigráfico integrado da seção eocênica do poço SE-2, no Baixo de Mosqueiro, com base em foraminíferos planctônicos, nanofósseis calcários e palinomorfos. Os resultados paleoambientais com base nas associações de foraminíferos bentônicos e de palinomorfos, integrados com os dados de isótopos estáveis (oxigênio e carbono), mostraram que os sedimentos foram depositados em paleobatimetrias batial superior a nerítico

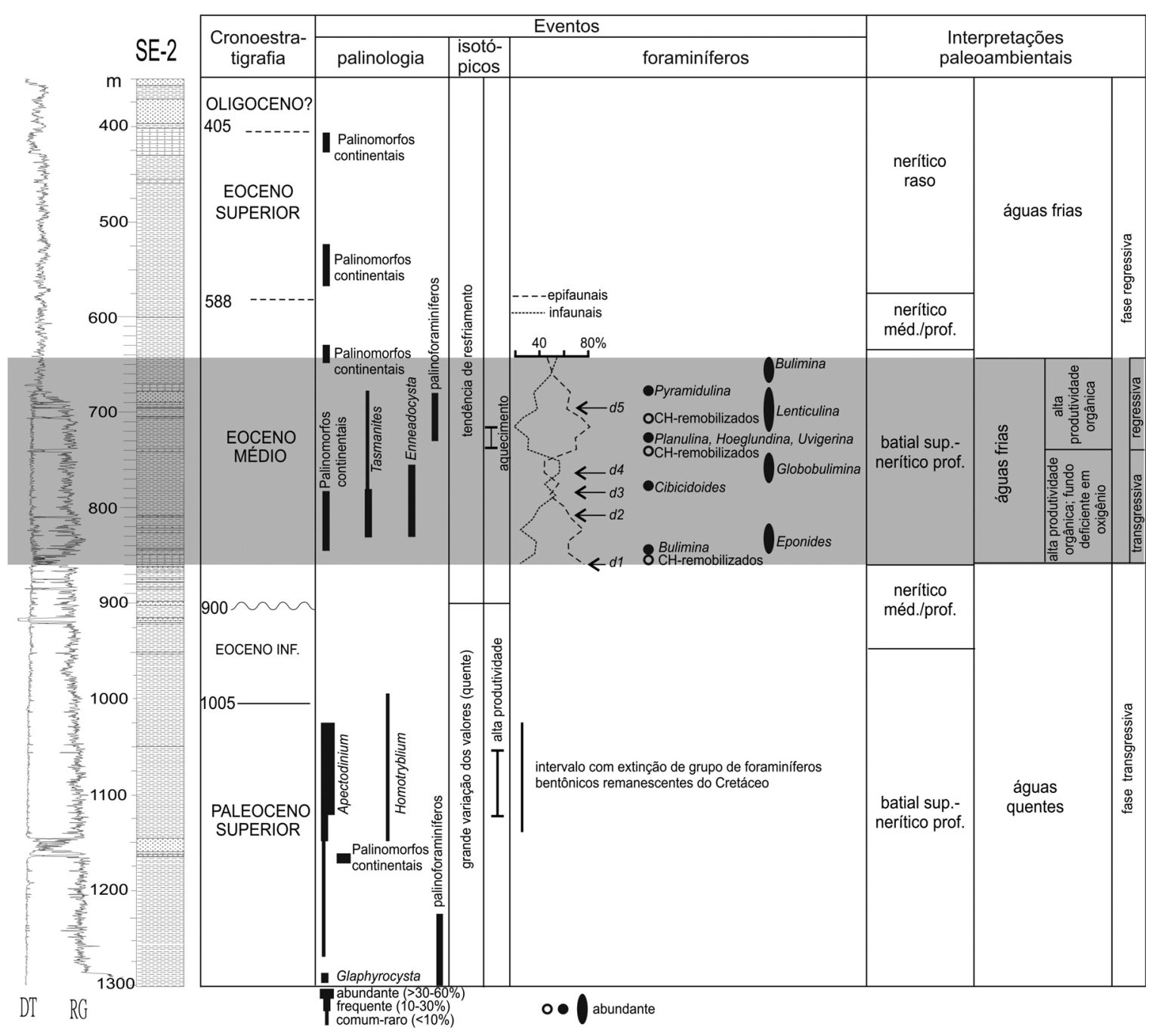

Figura 9. Sucessão das abundâncias relativas dos foraminíferos bentônicos e palinomorfos do poço SE-2 e interpretações paleoambientais.

Figure 9. Relative abundance of palynomorph and benthonic foraminifera of the well SE-2 and paleoenvironmental interpretations. 
profundo, alta produtividade orgânica no meio aquoso e condições de fundo deficientes em oxigênio. Verificou-se uma relação positiva entre as abundâncias de alguns grupos e morfogrupos de foraminíferos com abundâncias dos palinomorfos continentais e marinhos. Os dados indicam que os sedimentos durante o Mesoeoceno foram depositados num contexto de tendência de resfriamento das águas conforme indicado pelas abundâncias de Enneadocysta e Tasmanites, e reforçado pelo sinal isotópico.

\section{AGRADECIMENTOS}

Os autores agradecem à Petrobras por permitir a publicação deste trabalho. Ao geólogo A.E. Sayão Sanjinés (Cenpes/BPA) pelas sugestões e críticas que muito contribuíram para esse manuscrito. Ao CNPq (bolsa iniciação científica de pesquisa) e à Petrobras (bolsa de estágio-visita) pelo apoio financeiro recebido durante o desenvolvimento da pesquisa. Aos técnicos R.S.M. da Costa (Laboratório de Microscopia Eletrônica de Varredura do Cenpes/BPA) pela captura das imagens dos foraminíferos. AA.T. Dias (Laboratório de Artes Gráficas/BPA) pelo apoio no tratamento das imagens dos foraminíferos.

\section{REFERÊNCIAS}

Antunes, R.L.; Oliveira, L.C.V.; Shimabukuro, S. \& Cunha, A.S. 1998. Calcareous nannofossil biozones of the Brazilian continental margin: evolution of a concept. In: INTERNATIONAL NANNOPLANKTON ASSOCIATION CONFERENCE, 7, 1998. Proceedings, Puerto Rico, INA.

Berggren, W.A. \& Pearson, P.N. 2005. A revised tropical to subtropical Paleogene planktonic foraminiferal zonation. Journal of Foraminiferal Research, 35:279-298. doi: 10.2113/35.4.279

Berggren, W.A.; Kent, D.V.; Swisher, C.C. III \& Aubry, M.-P. 1995. A revised Cenozoic geochronology and chronostratigraphy. In: W.A. Berggren; D.V. Kent; M.-P. Aubry \& J. Hardenbol (eds.) Geochronology, time scales and global stratigraphic correlation, Cambridge University Press, p. 129-212. doi: 10.2110/pec.95.04.0129

Berggren, W.A.; Pearson, P.N.; Huber, B.T. \& Wade, B.S. 2006. Taxonomy, bostratigraphy, and phylogeny of Eocene Acarinina. In: P.N. Pearson; R.K. Olsson; B.T. Huber; C. Hemleben \& W.A. Berggren (eds) Atlas of Eocene Planktonic Foraminifera, Philadelphia, Cushman Foundation, p. 257-326 (Special Publication 41).

Bohaty, S. \& Zachos, J.C. 2003. Significant Southern Ocean warming event in the late middle Eocene. Geology, 31:1017-1020. doi: 10.1130/G19800.1

Bolli, H.M.; Beckmann, J-P. \& Saunders, J.B. 1994. Benthic foraminiferal biostratigraphy of the South Caribbean Region. $1^{\text {st }}$ ed. Cambridge, Cambridge University Press, 408 p. doi: 10.1017/CBO9780511564406

Bolli, H.M.; Saunders, J.B. \& Perch-Nielsen, K. 1985. Plankton Stratigraphy: planktic foraminifera, calcareous nannofossils and calpionellids. $1^{\text {st }}$ ed. Cambridge, Cambridge University Press, 328 p.

Campos Neto, O.P.A.; Souza, L.W. \& Cruz, F.E.G. 2007. Bacia de Sergipe-Alagoas. Boletim de Geociências da Petrobras, 15:405-415.
Corliss, B.H. 1983. Distribution of Holocene deep-sea benthonic foraminifera in the southwest Indian Ocean. Deep Sea Research Part A. Oceanographic Research Papers, 30:95-117. doi: 10.1016/0198-0149(83)90064-X

Costa, D.S. 2004. Estudos paleoecológicos e bioestratigráficos, com base em foraminiferos, no Cretáceo Superior (Santoniano - Maastrichtiano) da Bacia do Ceará (sub-bacia de Mundaú). Programa de Pós-graduação em Geologia, Universidade do Estado do Rio de Janeiro, Dissertação de Mestrado, 2 vols.

Crouch, E.; Brinkhuis, H.; Visscher, H.; Adatte, T. \& Bolle, M.-P. 2003. Late Paleocene-Early Eocene dinoflagellate cyst records from the Thetys: further observations on the global distribution of Apectodinium. In: S.L Wing; P.D. Gingerich; B. Schimitz \& E. Thomas (eds.) Causes and consequences of globally warm climates in the Early Paleogene, Boulder, The Geological Society of America, p. 113-132 (Special Paper 369). doi: 10.1130/0-8137-2369-8.113

Crouch, E.M.; Heilmann-Clausen, C.; Brinkhuis, H.; Morgans, H.E.G.; Rogers, K.M.; Egger, H. \& Schmitz, B. 2001. Global dinoflagellate event associated with the late Paleocene thermal maximum. Geology, 29:315-318. doi: 10.1130/0091-7613(2001)029<0315:GDEAWT>2.0.CO;2

Feijó, F.J. 1994. Bacias de Sergipe e Alagoas. Boletim de Geociências da Petrobras, 8:149-162.

Ferreira, E.P. 2004. Palinoestratigrafia e paleoecologia da seção paleocênica-eocênica da Bacia de Sergipe: uma contribuição para os estudos de estratigrafia de seqüencias. Programa de Pós-graduação em Geologia, Universidade Federal do Rio de Janeiro, Tese de Doutorado, 2 vols.

Ferreira, E.P.; Viviers, M.C. \& Galm, P.C. 2006. Apectodinium acme in the Paleocene-Eocene transition of the Sergipe basin. In: CLIMATE \& BIOTA OF THE EARLY PALEOGENE INTERNATIONAL MEETING AND FIELD TRIPS, 2006. Abstracts, Bilbao, ISPS, p. 42.

Goldstein, S.T. 1999. Foraminifera: a biological overview. In: B.K. Sen Gupta (ed.) Modern Foraminifera, Kluwer Academic Publishers, p. 37-55. doi: 10.1007/0-306-48104-9_3

Gradstein, F.M.; Ogg, J.O.; Schmitz, M. \& Ogg, G. 2012. The Geologic Time Scale. $1^{\text {st }}$ ed. Oxford, Elsevier, 1140 p.

Guy-Ohlson, D. 1996. Green and blue-green algae: Prasinophycean algae. In: J. Jansonius \& D.C. McGregor (eds.) Palynology: principles and applications, American Association of Stratigraphic Palynologists Foundation, p. 181-189.

Iaccarino, S.M. \& Premoli Silva, I. 2005. Practical Manual of Oligocene to Middle Miocene Planktonic Foraminifera. Perugia-Parma-Milano, International School on Planktonic Foraminifera, Universita degli Studi di Perugia/Università degli Studi di Parma/Universita degli Studi di Milano, $124 \mathrm{p}$.

Jackson, J.A. 1997. Glossary of Geology. $4^{\text {th }}$ ed. Alexandria, American Geological Institute, 769 p.

Jones, R.W. \& Charnock, M.A. 1985. "Morphogroups" of agglutinating Foraminifera. Their life positions and feeding habitats and potential applicability in (palaeo)ecological studies. Revue de Paléobiologie, 4:311-320.

Kennet, J.P. \& Stott, L.D. 1991. Abrupt deep-sea warning, palaeoceanographic changes and benthic extinctions at the end of the Palaeocene. Nature, 353:225-229. doi: 10.1038/353225a0

Knox, R.W.O'B. 1996. Correlation of the early Paleogene in northwest Europe: an overview. In: R.W. O'B Knox; R.M. Corfield \& R.E. Dunay (eds.) Correlation of the Early Paleogene in Northwest Europe, London, Geological Society, p. 1-11 (Special Publication 101). doi: 10.1144/GSL.SP.1996.101.01.01 
Köthe, A. 1990. Paleogene dinoflagellates from northwest Germanybiostratigraphy and paleoenvironment. Geologisches Jahrbuch, 118:1-111.

Koutsoukos, E.A.M. \& Hart, M.B. 1990. Cretaceous foraminiferal morphogroup distribution patterns, palaeocommunities and trophic structures: a case study from Sergipe Basin, Brazil. Transactions of the Royal Society of Edinburgh, Earth Sciences, 81:221-246. doi: 10.1017/S0263593300005253

Loeblich, A.R. \& Tappan, H. 1988. Foraminiferal genera and their classification. $1^{\text {st }}$ ed. New York, Van Nostrand Reinhold Company, $970 \mathrm{p}$.

Maizatto, J.R.; Ferreira, E.P. \& Lana, C.C. 2004. A utilização de Tasmanites como indicador paleoecológico. In: REUNIÃO DE PALINÓLOGOS E PALEOBOTÂNICOS, 11, 2004. Boletim de Resumos, Gramado, SBP-ALLP, p. 94.

Martini, E. 1971. Standard Tertiary and Quaternary calcareous nannoplankton zonation. In: A. Farinacci (ed.) Proceedings of the Second Planktonic Conference, Tecnoscienza, p. 739-785.

Martinis, E. 1996. Foraminíferos planctônicos do Paleoceno-Eoceno da Bacia de Sergipe: taxonomia e bioestratigrafia. Programa de Pós-graduação em Geologia, Universidade Federal do Rio de Janeiro, Dissertação de Mestrado, 103 p.

Murray, J.W. 1991. Ecology and palaeoecology of benthic Foraminifera. New York, Longman, 402 p.

Noguti, I. \& Santos, J.F. 1972. Zoneamento preliminar por foraminíferos planctônicos do Aptiano ao Mioceno na plataforma continental do Brasil. Boletim Técnico da Petrobras, 15:265-283.

Ortiz, S. \& Thomas, E. 2006. Lower-middle Eocene benthic foraminifera from the Fortuna Section (Bentic Cordillera, southeastern Spain). Micropaleontology, 52:97-150. doi: 10.2113/gsmicropal.52.2.97

Pearson, P.N.; Olsson, R.K.; Huber, B.T.; Hemleben, C. \& Berggren, W.A. 2006. Atlas of Eocene planktonic Foraminifera. Philadelphia, Cushman Foundation, 514 p. (Special Publication 41).

Premaor, E.; Souza, P.A.; Ferreira, E.P. \& Guerstein, G.R. 2013. Sobre a ocorrência de Enneadocysta dictyostila nas associações de cistos de dinoflagelados do Eoceno da Bacia de Pelotas e seu significado paleoceanográfico. In: SIMPÓSIO BRASILEIRO DE PALEOTÂNICA E PALINOLOGIA, 14, 2013. Resumos, Rio de Janeiro, SBP-ALPP, p. 136.

Sen Gupta, B.K. 1999. Modern Foraminifera. $1^{\text {st }}$ ed. Grain Britain, Kluwer Academic Publishers, 384 p.

Severin, K.P. 1983. Test morphology in benthic foraminifera as a discriminator of biofacies. Marine Micropaleontology, 8:65-76. doi: 10.1016/0377-8398(83)90005-1
Sluijs, A.; Pross, J. \& Brinkhuis, H. 2005. From greenhouse to icehouse; organic-walled dinoflagellate cysts as paleoenvironmental indicators in the Paleogene. Earth-Science Reviews, 68:281-315. doi. 10.1016/j.earscirev.2004.06.001

Souza-Lima, W. 2006. Litoestratigrafia e evolução tectonosedimentar da bacia de Sergipe Alagoas. Boletim da Fundação Paleontológica Phoenix, 89:1-10.

Spezzaferri, S. 1994. Planktonic foraminiferal biostratigraphy and taxonomy of the Oligocene and lower Miocene in the oceanic record. An overview. Paleontographia Italica, 81:1-187.

Thomas, E \& Shackleton, N.J. 1996. The Paleocene-Eocene benthic foraminiferal extinction and stable isotope anomalies. London, Geological Society, p. 401-441 (Special Publications 101). doi: 10.1144/GSL.SP.1996.101.01.20

Vandenberghe, N.; Hilgen, F.J. \& Speijer, R.P. 2012. The Paleogene Period. In: F.M. Gradstein; J.O. Ogg; M. Schmitz \& G. Ogg (eds.) The Geologic Time Scale, Elsevier, p. 855-921. doi: 10.1016/ B978-0-444-59425-9.00028-7

Viviers, M.C. \& Ferreira, E.P. 2006a. "Flysch-type" foraminiferal assemblages in Brazilian Paleocene-Eocene sedimentary successions. In: CLIMATE \& BIOTA OF THE EARLY PALEOGENE - INTERNATIONAL MEETING AND FIELD TRIPS, 2006. Abstracts, Bilbao, ISPS, p. 143.

Viviers, M.C. \& Ferreira, E.P. 2006b. Paleocene-Eocene Brazilian sedimentary successions and their "flysch type" foraminiferal assemblages. Anuário do Instituto de Geociências da UFRJ, 29:575.

Williams, G.L.; Ascoli, P.; Barss, M.S.; Bujak, J.P.; Davies, E.H.; Fensome, R.A. \& Williamson, M.A. 1990. Biostratigraphy and related studies. In: M.J. Keen \& G.L. Williams (eds.) Geology of the continental margin of Eastern Canada, Geological Survey of Canada, p. 87-137.

Wrenn, J.H. \& Beckman, S.W. 1982. Maceral, total organic carbon, and palynological analyses of Ross Ice Shelf Project site J9 cores. Science, 216:187-189. doi: 10.1126/science.216.4542.187

Zachos, J.C.; Lohmann, K.C.; Walker, J.C.G. \& Wise, S.W. 1993. Abrupt climate change and transient climates during the Paleogene: a marine perspective. The Journal of Geology, 101:191-213.

Zachos, J.C.; Dickens, G.R. \& Zeebe, R.E. 2008. A nearly Cenozoic perspective on greenhouse warning and carbon-cycle dynamics. Nature, 451:279-283. doi: 10.1038/nature06588

Received in April, 2015; accepted in October, 2015. 
Anexo 1. Lista de espécies de foraminíferos planctônicos identificados neste trabalho.

Appendix 1. List of species of planktonic foraminifers identified in this work.

Acarinina bullbrooki Bolli, 1957

Acarinina praetopilensis Blow, 1979

Acarinina punctocarinata Fleisher, 1974

Acarinina rohri Brönnimann \& Bermúdez, 1953

Acarinina topilensis (Cushman, 1925)

Acarinina ex. gr. wilcoxensis Cushman \& Ponton, 1932

Catapsydrax dissimilis Cushman \& Bermúdez, 1937

Catapsydrax unicavus Bolli, Loeblich \& Tappan, 1957

Dentoglobigerina galavisi Bermúdez, 1961

Dentoglobigerina larmeui Akers, 1955

Globanomalina pseudomenardii Bolli, 1957

Globigerina bulloides d'Orbigny, 1826

Globigerina praebulloides Blow, 1959

Globigerina prasaepis Blow, 1969

Globigerina tapuriensis Blow \& Banner, 1962

Globigerina venezuelana Hedberg, 1937

Globigerinatheka barri Brönnimann, 1952

Globigerinatheka euganea Proto Decima \& Bolli, 1970

Globigerinatheka index Finlay, 1939

Globigerinatheka kugleri Bolli, Loeblich \& Tappan, 1957

Globigerinatheka korotkovi Keller, 1946

Globigerinatheka luterbacheri Bolli, 1972

Globigerinatheka mexicana Cushman, 1925

Globigerinatheka semiinvoluta Keijzer, 1945

Globigerinatheka subconglobata Shutskaya, 1958

Globoturborotalita martini Blow \& Banner, 1962

Guembelitrioides nuttalli Hamilton, 1953

Morozovella crater Hornibrook, 1958

Morozovella velascoensis Cushman, 1925

Morozovelloides bandyi Fleisher, 1974

Morozovelloides crassatus Cushman, 1925

Morozovelloides lehneri Cushman \& Jarvis, 1929

Morozovelloides cf. coronatus Blow, 1979

Neogloboquadrina sp.

Orbulinoides beckmanni Saito, 1962

Paragloborotalia griffinoides Olsson \& Pearson, 2006

Paragloborotalia nana Bolli, 1957

Paragloborotalia opima opima Bolli, 1957

Parasubbotina griffinae Blow, 1979

Parasubbotina eoclava Coxall, Huber \& Pearson, 2003

Pseudoglobigerinella bolivariana Petters, 1954

Subbotina eocaena Guembel, 1968

Subbotina hagni Gohrbandt, 1967

Subbotina senni Beckmann, 1953

Subbotina yeguaensis Weinzierl \& Applin, 1929

Tenuitellinata angustiumbilicata Bolli, 1957

Turborotalia altispiroides Bermúdez, 1961

Turborotalia ampliapertura Bolli, 1957

Turborotalia cerroazulensis Cole, 1928

Turborotalia increbescens (Bandy, 1949)

Turborotalia pomeroli Toumarkine \& Bolli, 1970

Turborotalia possagnoensis Toumarkine \& Bolli, 1970) 